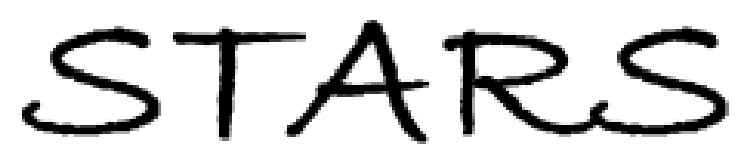

University of Central Florida

STARS

Faculty Bibliography 1990s

Faculty Bibliography

1-7-1995

\title{
Mathematical-Modeling Of Key-Hole Laser-Welding
}

\author{
A. Kar \\ University of Central Florida \\ J. Mazumder
}

Find similar works at: https://stars.library.ucf.edu/facultybib1990

University of Central Florida Libraries http://library.ucf.edu

This Article is brought to you for free and open access by the Faculty Bibliography at STARS. It has been accepted for inclusion in Faculty Bibliography 1990s by an authorized administrator of STARS. For more information, please contact STARS@ucf.edu.

\section{Recommended Citation}

Kar, A. and Mazumder, J., "Mathematical-Modeling Of Key-Hole Laser-Welding" (1995). Faculty Bibliography 1990s. 762.

https://stars.library.ucf.edu/facultybib1990/762

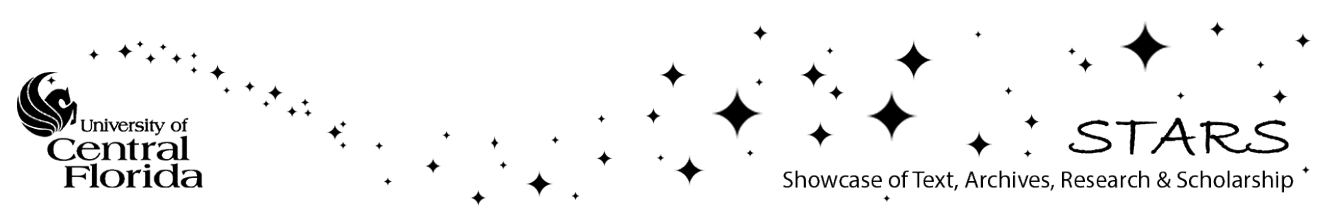




\section{Mathematical modeling of key-hole laser welding}

Cite as: Journal of Applied Physics 78, 6353 (1995); https://doi.org/10.1063/1.360686

Submitted: 12 July 1995 . Accepted: 25 July 1995 . Published Online: 17 August 1998

A. Kar, and J. Mazumder

ARTICLES YOU MAY BE INTERESTED IN

Dynamics of keyhole and molten pool in laser welding

Journal of Laser Applications 10, 247 (1998); https://doi.org/10.2351/1.521858

Keyhole modeling during laser welding

Journal of Applied Physics 87, 4075 (2000); https://doi.org/10.1063/1.373033

Heat transfer model for cw laser material processing

Journal of Applied Physics 51, 941 (1980); https://doi.org/10.1063/1.327672

Lock-in Amplifiers

... and more, from DC to $600 \mathrm{MHz}$ Watch 


\title{
Mathematical modeling of key-hole laser welding
}

\author{
A. Kar \\ Center for Research and Education in Optics and Lasers (CREOL), Mechanical and Aerospace engineering \\ Department, University of Central Florida, Orlando, Florida 32826 \\ J. Mazumder \\ Center for Laser-Aided Materials Processing (CLAMP), Mechanical and Industrial Engineering \\ Department, University of Illinois at Urbana-Champaign, Urbana, Illinois 61801
}

(Received 12 July 1995; accepted for publication 25 July 1995)

\begin{abstract}
Laser welding is a unique way of joining materials with less thermal distortion and minimum metallurgical damage to the workpiece. The molten pool formed during welding determines the shape of the final welded region. At high laser intensities, the molten material vaporizes and a key hole is formed during the welding process. This vapor and the shape of the molten pool affect the absorption of laser at the liquid surface. The forces generated at the liquid-vapor interface due to surface tension gradient induce thermocapillary convection in the weld pool. This paper presents a mathematical model by considering these surface forces and the energy balance at the liquid-vapor and solid-liquid interfaces. The model is used to predict the surface velocity and temperature distributions, weld pool shape, key-hole depth and diameter. The velocity field is found to be large in the radial and azimuthal directions before the key hole is formed, and it changes to a radially and axially dominant field after the formation of the key hole. The results of this model are also compared with experimental data. (C) 1995 American Institute of Physics.
\end{abstract}

\section{INTRODUCTION}

An important feature of a laser beam is that it allows us to deliver a large amount of energy to the point where it is needed the most. For this reason, laser technology provides a unique means of joining materials with minimum thermal distortion and metallurgical damage to the workpiece. Also, laser welding can be performed at a high speed. Since a laser beam is an inertialess and contactless tool, the laser welding process can be automated and controlled easily. At present, lasers are used to weld thin materials. When the thickness of the workpiece is small, a liquid pool of molten material is formed during the welding process, and the shape of the pool is affected by the thermocapillary convection. High laser intensity is required for thick-section laser welding which is usually referred to as the key-hole welding or deeppenetration welding. At high laser intensities, the material is melted as well as vaporized, and a key hole is formed. Ionization can also occur in this vapor phase depending on the laser intensity. The key hole contains this partially ionized vapor which can absorb a major portion of the laser energy and affect the propagation of the laser beam. Such key-hole phenomena limit the thickness of the workpiece that can be welded with high intensity laser beams. A proper understanding of the key-hole phenomena is necessary to carry out deep-penetration welding.

A lot of work has been done to understand the convection processes and the free-surface deformation of the weld pools in the absence of any key hole. Mazumder ${ }^{1}$ has presented an overview of melt dynamics. The importance of convection in weld pool was realized as early as $1947 .^{2}$ Cline and Anthony ${ }^{3}$ provided an analytic treatment for the heating and melting of materials under a scanning laser or electron beam. Andrews and Craine ${ }^{4}$ studied the fluid flow in a hemispherical weld pool produced by a distributed current source by solving the Navier-Stokes equation without considering the nonlinear convective terms. Atthey ${ }^{5}$ solved the nonlinear fluid flow equations numerically in a weld pool induced by a distributed source of current. He obtained solutions in spherical polar coordinates by assuming hemispherical weld pool, axial symmetry and a flat free surface. Kou et $_{\text {al. }}{ }^{6}$ presented a model for surface melting and solidification with a moving heat source. Oreper et al. ${ }^{7}$ developed a two-dimensional model to study temperature distribution and convection due to buoyancy, electromagnetic, and surface tension forces in arc weld pools. They assumed a planer free surface and a laminar flow under steady state condition, and specified the weld pool shape based on the heat conduction solution due to a distributed heat source. Oreper and Szekely ${ }^{8}$ presented a model for the transient tungsten-inert-gas (TIG) welding process. Chan et al. ${ }^{9}$ developed a two-dimensional transient convective heat transfer model for laser melted pools. Later, they ${ }^{10,11}$ presented a three-dimensional axisymmetric model and a three-dimensional perturbation model to examine the effects of thermocapillary convection in laser melted pools. Kou and Wang ${ }^{12}$ developed a three-dimensional steady-state model for a moving arc welding process to examine the convection due to buoyancy, electromagnetic and thermocapillary forces assuming a flat free surface. Kou and Sun ${ }^{13}$ presented a two-dimensional model convection in a melt pool formed by a stationary arc. Kou and Wang ${ }^{14}$ developed a three-dimensional steady-state model for laser welding. Basu and Srinivasan, ${ }^{15}$ and Basu and Date ${ }^{16,17}$ carried out numerical studies of steady state and transient laser melting problems.

The above-mentioned studies are based on the assumption that the free surface of the melt pool is flat. Anthony and Cline $^{18}$ studied the surface rippling induced by surface tension gradients during laser surface melting and alloying. Zacharia et al. ${ }^{19,20}$ and Tsai and $\mathrm{Kou}^{21}$ calculated the shape of the melt pool free surface for arc welding. Zacharia et al. ${ }^{20}$ 
solved the integral form of the governing conservation equations using a discrete element analysis to model a transient three-dimensional gas-tungsten-arc (GTA) welding process. They determined the shape of the free surface and found that the free surface has a depression under the arc and it bulges upward at the outer edge of the melt pool. Paul and Debroy ${ }^{22}$ presented a two-dimensional transient model for low-power conduction mode laser welding. They also determined the shape of the free surface and found that the free-surface bulges upward under the beam at the pool center and near the solid-liquid interface, and the pool has a depression between these two regions. Tsai and Kou, ${ }^{23,24}$ Kreutz and Pirch, ${ }^{25}$ and $\mathrm{Zehr}^{26}$ developed models to show small deformation of the weld pool free surface during laser welding. Thompson and Szekely, ${ }^{27}$ and Choo et al. ${ }^{28}$ used a specified deformed surface to model the weld pool during arc welding. These studies were concerned with a very small deformation of the weld pool free surface.

A large deformation of the free surface is encountered during key-hole welding due to the formation of a vapor and plasma-filled cavity. Dowden et al. ${ }^{29}$ presented a key-hole model for deep penetration laser welding, and pointed out that their model does not provide a good description of the weld pool at the upper end. Postacioglu et al. ${ }^{30}$ modeled the bulging in the liquid region at the mouth of the key hole by calculating only the axial flow of the molten material due to the pressure inside the key hole. Steen et al. ${ }^{31}$ developed a model for laser key-hole welding of infinitely thick substrates by considering the laser beam as a combination of a point and a line source. Akhter et al $^{32}$ modified the model of Ref. 31 to analyze the key-hole welding of a workpiece of finite thickness. Dowden et al. ${ }^{33}$ presented a simple model just for the laser-plasma interaction ignoring fluid dynamical effects in laser key-hole welding. Dowden et al. $^{34}$ studied the dynamics of only the axial flow of vapor in the key hole at medium welding speeds, and pointed out that there may be no solutions consistent with the assumptions of their model for certain welding conditions. Beck et $a l^{35}$ modeled the interaction between the melt and key hole assuming circular key holes for low welding speeds. Metzbower ${ }^{36}$ calculated the size and temperature of the key hole and melt pool on the top surface of the workpiece based on the laser power loss due to evaporation and a minimum laser power density required to generate a key hole. Lambrakos et al. ${ }^{37}$ presented a time-dependent three-dimensional model for deep penetration laser welding by considering the fluid flow in the molten region and simplifying some of the boundary conditions. Tix and Simon ${ }^{38}$ examined the transport of electrons, ions, and neutrals in the partially ionized vapor formed in the key hole. Kroos et al. $^{39}$ studied the stability of the key hole ignoring hydrodynamics in the melt and vapor phases and assuming the key hole to be cylindrical. For continuous wave (cw) and pulsed laser welding applications, Kroos et $a l^{40}$ presented a model for dynamic behavior of the key hole by assuming that the flow of the melt is only in the radial direction, and the key hole is cylindrical.

The purpose of this paper is to show how the momentum balance at the liquid-vapor interface, and the energy balance at the solid-liquid and liquid-vapor interfaces can be utilized

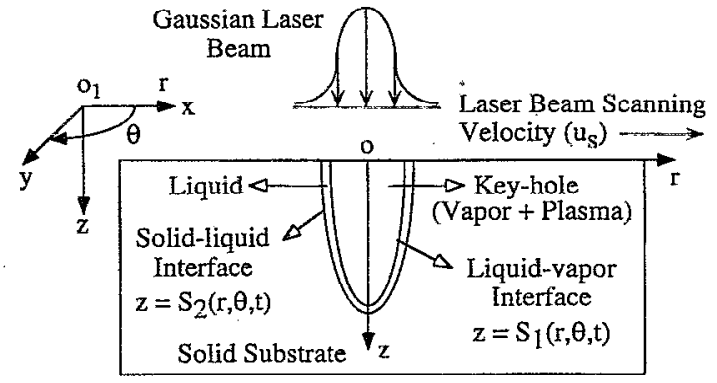

FIG. 1. Geometric model for laser key-hole welding.

to predict the velocity and temperature distributions at the free surface and the key-hole shape. The velocity field is found to be dominant in the radial and azimuthal directions before the key hole is formed, and it becomes large in the radial and axial directions after the formation of the key hole. The depth and width of the weld pool calculated using the model of this paper are found to compare well with experimental data.

\section{MATHEMATICAL MODEL}

During laser key-hole welding, the temperature varies by a large amount over a small distance. This produces a large surface tension gradient that generates a shear stress at the liquid-vapor interface to induce flow in the molten material. A typical key-hole welding process and the cylindrical coordinate system $(r, \theta, z)$ used in the model of this paper are shown in Fig. 1. The point $o$ on the substrate surface represents the origin of the coordinate system. $o_{1}$ represents the origin in the Cartesian coordinate $(x, y, z)$ system, which is also shown in Fig. 1 to indicate that $\theta$ is measured in the clockwise direction from the $x$ axis. The direction of the laser beam scanning velocity $u_{s}$ coincides with that of the $x$ axis, that is, the laser beam is scanned along the radial direction $r$ for the azimuthal angle $\theta=0$. Therefore, the workpiece moves in the negative $x$ direction with respect to a viewer sitting at the laser beam. A Gaussian laser beam is focused on the top surface of the workpiece to produce a key hole as shown in Fig. 1. The key hole is filled with vapor which can also be partially ionized. $z=S_{1}(r, \theta, t)$ and $z=S_{2}(r, \theta, t)$ are equations for two surfaces that represent the liquid-vapor and solid-liquid interfaces, respectively. These two interfaces are the boundaries of the molten material.

The velocity and temperature fields in the molten material can be obtained by considering the following momentum, energy, and mass conservation equations: ${ }^{41}$

$$
\begin{aligned}
& \rho_{l}\left(\frac{\partial \mathbf{u}_{l}}{\partial t}+\left(\mathbf{u}_{l} \cdot \nabla\right) \mathbf{u}_{l}\right)=\rho_{l} \mathbf{g}-\nabla p_{l}+\mu_{l} \nabla^{2} \mathbf{u}_{l}, \\
& \rho_{l} c_{p l}\left(\frac{\partial T_{l}}{\partial t}+\left(\mathbf{u}_{l} \cdot \nabla\right) T_{l}\right)=k_{l} \nabla^{2} T_{l}, \\
& \nabla \cdot \mathbf{u}_{l}=0 .
\end{aligned}
$$

Here $\rho_{l}, \mu_{l}, c_{p l}, k_{l}, \mathbf{u}_{l}, \mathbf{g}, p_{l}$, and $T_{l}$ are the density, viscosity, specific heat at constant pressure, thermal conductiv- 
ity, velocity vector, acceleration due to gravity, pressure, and temperature of the molten material, respectively. $t$ and $\nabla$ are the time variable and "del" operator, respectively.

In addition to the above-mentioned three equations, the heat transport processes in the solid substrate and vapor phase need to be considered in order to determine the flow of thermal energy from the molten material across the interfaces. These conservation equations have to be solved by considering the appropriate boundary conditions. No-slip boundary condition is used at the solid-liquid interface, that is $u=0$ at $z=S_{2}(r, \theta, t)$. At the free surface, that is, at the liquid-vapor interface, the boundary conditions for Eq. (1) are obtained by conserving the momentum in the normal and tangential directions with respect to the free surface, which results in the following expressions.

The normal component of the momentum balance at the liquid-vapor interface yields ${ }^{41}$

$$
\begin{aligned}
m_{l} \mathbf{n} \cdot\left(\mathbf{u}_{l}-\mathbf{u}_{i v}\right)+m_{g} \mathbf{n} \cdot\left(\mathbf{u}_{g}-\mathbf{u}_{i v}\right)-\mathbf{n} \cdot\left[\mathbf{n} \cdot\left(\tau_{l}-\tau_{g}\right)\right]+\mathbf{n} \\
\cdot \nabla_{s} \sigma-\left(\nabla_{s} \cdot \mathbf{n}\right) \sigma \mathbf{n} \cdot \mathbf{n}=0
\end{aligned}
$$

and the tangential component of the momentum balance at the liquid-vapor interface yields

$$
\mathbf{t} \cdot \nabla_{s} \sigma-\mathbf{t} \cdot\left[\mathbf{n} \cdot\left(\tau_{l}-\tau_{g}\right)\right]=0,
$$

where $m_{l}$ and $m_{g}$ are the mass fluxes of liquid and vapor, respectively, in the normal direction. $\mathbf{n}$ and $\mathbf{t}$ are unit normal and unit tangential vectors, respectively. $\mathbf{u}_{g}$ and $\mathbf{u}_{i v}$ are the velocities of the vapor at the liquid-vapor interface and the free surface (vaporization interface), respectively. $\tau_{l}$ and $\tau_{g}$ are the stress tensors of the liquid and vapor phases, respectively, at the liquid-vapor interface. $\nabla_{s}$ and $\sigma$ are the surface gradient and surface tension, respectively, at the liquid-vapor interface. Similarly, the balance of energy flow along the normal to the liquid-vapor and solid-liquid interfaces provides the necessary boundary conditions for the energy transfer equations. The energy balance at the solid-liquid interface yields

$$
k_{s} \mathbf{n} \cdot \nabla T_{s}-k_{l} \mathbf{n} \cdot \nabla T_{l}=\rho_{s} L_{m} \mathbf{n} \cdot \mathbf{u}_{i m}
$$

and the energy balance at the liquid-vapor interface yields

$$
k_{l} \mathbf{n} \cdot \nabla T_{l}-k_{g} \mathbf{n} \cdot \nabla T_{g}+A \mathbf{I} \cdot \mathbf{n}=\rho_{l} L_{v} \mathbf{n} \cdot\left(\mathbf{u}_{l}-\mathbf{u}_{i v}\right),
$$

where $k_{s}$ and $k_{g}$ are the thermal conductivities of the solid substrate and vapor phase, respectively. $T_{s}$ and $T_{g}$ are the temperatures of the solid substrate and vapor phase, respectively. $\rho_{s}$ is the density of the solid substrate. $L_{m}$ and $L_{v}$ are the latent heats of melting and vaporization, respectively. $\mathbf{u}_{i m}$ is the velocity of the solid-liquid interface (melting interface). $I$ is the incident laser intensity at the liquid-vapor interface and $A$ is the absorptivity.

It should be noted that Eqs. (1)-(7) represent a timedependent three-dimensional problem where the equations are coupled and highly nonlinear. This problem is extremely difficult to solve without making any simplification. For this reason, the boundary conditions have been simplified by ignoring the second and higher order derivatives, and the products of any two derivatives. At the liquid-vapor interface, $z=S_{1}(r, \theta, t)$, we obtain the following four expressions:

$$
\begin{aligned}
& -\mu_{l}\left(\frac{\partial u_{r}}{\partial z}+\frac{\partial u_{z}}{\partial r}\right)+\sigma_{T} \frac{\partial T_{l}}{\partial r}=0, \\
& -\mu_{l}\left(\frac{\partial u_{\theta}}{\partial z}+\frac{1}{r} \frac{\partial u_{z}}{\partial \theta}\right)+\sigma_{T} \frac{1}{r} \frac{\partial T_{l}}{\partial \theta}=0, \\
& 2 \mu_{l} \frac{\partial u_{z}}{\partial z}=p_{l}-p_{g}, \\
& k_{l} \frac{\partial T_{l}}{\partial z}+A I_{z}=\rho_{l} L_{v}\left(\frac{\partial S_{1}}{\partial t}-u_{z}\right),
\end{aligned}
$$

and at the solid-liquid interface, $z=S_{2}(r, \theta, t)$, we obtain the following expression:

$$
k_{s} \frac{\partial T_{s}}{\partial z}-k_{l} \frac{\partial T_{l}}{\partial z}=\rho_{s} L_{m} \frac{\partial S_{2}}{\partial t},
$$

where $u_{r}, u_{\theta}, u_{z}$ are the radial, azimuthal, and axial components, respectively, of the velocity vector $\mathbf{u}_{l}, \sigma_{T}$ is the temperature coefficient of the surface tension, that is, $\sigma_{T}=\partial \sigma / \partial T_{l} . I_{z}$ is the $z$ component of the laser intensity $\mathbf{I}$. Since the physical phenomena at the boundaries are the most dominant processes that influence the flow field in the melt and affect the laser-material interactions, the simplified Eqs. (8) -(12) are solved in this paper as discussed below.

The key-hole welding problem of this paper is symmetrical about the laser beam scanning direction. Due to this symmetry, the problem is solved in the region $0 \leqslant \theta \leqslant \pi$, where $u_{r}, u_{z}, T_{l}, S_{1}$, and $S_{2}$ can be expressed in terms of the Fourier cosine series. However, $u_{\theta}$ has to be expressed in terms of the Fourier sine series to conform with the boundary condition at the solid-liquid interface and the mass conservation equation. For example, $T_{l}$ can be written as

$$
T_{l}(r, \theta, z, t)=\sum_{m=0}^{\infty} T_{l m}(r, m, z, t) \frac{\cos m \theta}{N_{m}} .
$$

Here $N_{m}$ is the normalization constant which is given by $N_{m}=\left(1+\delta_{m 0}\right) \pi / 2$, where $\delta_{m 0}$ is the Dirac delta function. Noting that $T_{l}$ must satisfy certain boundary conditions, $T_{l m}$ can be chosen in the following forms:

$$
\begin{aligned}
T_{l 0}= & N_{0}\left(T_{v}-\left(T_{v}-T_{m}\right) \frac{r^{2}}{r_{0}^{2}}\right), \\
T_{l 1}= & N_{1}\left(T_{v}-\left(T_{v}-T_{m}\right) \frac{r^{2}}{r_{0}^{2}}\right) \frac{T_{v}-T_{m}}{T_{v}}\left(1-\frac{r}{r_{0}}\right) \\
& \times\left(\frac{r^{2}}{r_{0}^{2}}\right) \exp \left(-u_{s} / u_{c}\right),
\end{aligned}
$$

where $T_{m}$ and $T_{v}$ are respectively the melting and vaporization temperatures of the workpiece. $r_{0}$ is the laser beam radius and $u_{c}$ is the characteristic velocity of the molten material. $u_{c}$ is determined by using the boundary layer theory, ${ }^{42}$ that is,

$$
u_{c}=\left(\frac{2.75\left|\sigma_{T}\right| A P}{2 \pi r_{0}^{2} \rho_{l} k_{l}^{0.58}\left(\mu_{l} c_{p l}\right)^{0.42}}\right)^{1 / 2},
$$

where $P$ is the incident laser power. The temperature gradients $\partial T_{s} / \partial z$ and $\partial T_{l} / \partial z$ are computed at the solid-liquid and 
TABLE I. Thermophysical properties of iron (Fe) that are used in this paper for mild steel.

\begin{tabular}{ll}
\hline \multicolumn{1}{c}{ Thermophysical properties } & \multicolumn{1}{c}{ Values } \\
\hline Density $\left(\rho_{s}\right)$ & $7015 \mathrm{~kg} \mathrm{~m}^{-3}$ \\
'Thermal conductivity $\left(k_{s}\right)$ & $78.2 \mathrm{~W} \mathrm{~m}^{-1} \mathrm{~K}^{-1}$ \\
Specific heat $\left(c_{p s}\right)$ & $456 \mathrm{~J} \mathrm{~kg}^{-1} \mathrm{~K}^{-1}$ \\
Melting temperature $\left(T_{m}\right)$ & $1809 \mathrm{~K}$ \\
Vaporization temperature $\left(T_{v}\right)$ & $3133 \mathrm{~K}$ \\
Latent heat of melting $\left(L_{m}\right)$ & $2.714 \times 10^{5} \mathrm{~J} \mathrm{~kg}^{-1}$ \\
Latent heat of vaporization $\left(L_{v}\right)$ & $6.078 \times 10^{6} \mathrm{~J} \mathrm{~kg} \mathrm{~g}^{-1}$ \\
Viscosity of liquid Fe at $T_{m}\left(\mu_{l}\right)$ & $1.813 \times 10^{-3} \mathrm{~N} \mathrm{~s} \mathrm{~m}^{-2}$ \\
Surface tension of liquid $\mathrm{Fe}$ at $T_{m}(\sigma)$ & $1.872 \mathrm{~N} \mathrm{~m}^{-1}$ \\
Temperature coefficient of surface & $-4.9 \times 10^{-4} \mathrm{~N} \mathrm{~m}^{-1} \mathrm{~K}^{-1}$ \\
$\quad$ tension for liquid Fe at $T_{m}\left(\sigma_{\tau}\right)$ & \\
\hline \hline
\end{tabular}

liquid-vapor interfaces, respectively, by assuming that the interface temperature drops to $1 / e$ of the interface temperature at a characteristic distance (thermal layer) $\delta_{t}$. Similarly, the velocity gradient $\partial u_{z} / \partial z$ is computed at the liquid-vapor interface by assuming that $u_{z}$ drops to $u_{z} / e$ at a characteristic distance (viscous layer) $\delta_{u}$ which is taken to be $\delta_{u}=\mu u_{s} r_{0} / \sigma$. With these simplifications, Eqs. (8)-(12) are solved numerically by marching forward in time.

\section{RESULTS AND DISCUSSION}

The above-mentioned model is used to study the velocity and temperature distributions at the free surface and to determine the shape of the key hole and weld pool during laser welding. The depth and width of the weld pool predicted by this model are also compared with experimental data which were obtained in laser key-hole welding experiments using mild steel. All the results of this paper are obtained for mild steel with the thermophysical properties listed in Table I. Due to the lack of data for mild steel, the thermophysical properties of mild steel are taken to be the same as those of iron. Also, the density, thermal conductivity and specific heat of iron are taken to be the same in the solid and liquid phases in this study.

For laser parameters, a $\mathrm{CO}_{2}$ laser of $10.6 \mu \mathrm{m}$ wavelength is used with laser beam radius $r_{0}=0.3 \mathrm{~mm}$ and incident laser powers $P=1480,1850$, and $2300 \mathrm{~W}$. As the laser power increases, more vapor is generated during laser welding. This vapor interacts with the incident laser beam and affects the amount of the laser energy reaching the surface of the workpiece. To account for this physical phenomenon, the absorptivity $A$ is taken to be $8 \%$ when the laser beam scanning speed $u_{s}=2.12 \mathrm{~cm} / \mathrm{s}$, and $A=17 \%$ and $15 \%$ for $P=1480$ and $1850 \mathrm{~W}$, respectively, when $u_{s}=4.23 \mathrm{~cm} / \mathrm{s}$. At a low scanning speed, the laser-material interaction time is large and consequently, a large amount of vapor is formed which reduces the amount of the laser energy reaching the substrate surface. For this reason, the value of the absorptivity $A$ for $u_{s}=2.12 \mathrm{~cm} / \mathrm{s}$ is chosen to be lower than the value of $A$ for $u_{s}=4.23 \mathrm{~cm} / \mathrm{s}$. Similarly, for a given scanning speed, an increase in the incident laser power leads to an increased amount of vapor generation and consequently the amount of laser energy reaching the substrate surface is re-

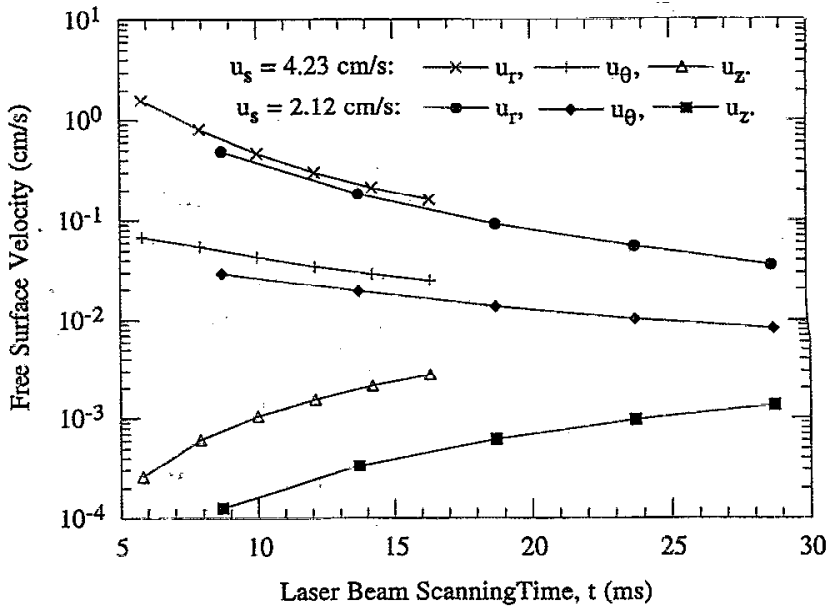

FIG. 2. Velocity components at $r=0.20041 \mathrm{~mm}$ and $\theta=10^{\circ}$ on the free surface during laser key-hole welding for incident laser power, $P=2300 \mathrm{~W}$ and laser beam radius, $r_{0}=0.3 \mathrm{~mm} . A=8 \%$ and $12 \%$ for $u_{s}=2.12$ and $4.23 \mathrm{~cm} / \mathrm{s}$, respectively.

duced. For this reason, the value of the absorptivity $A$ for $P=1850 \mathrm{~W}$ is taken to be slightly less than the value of $A$ for $P=1480 \mathrm{~W}$.

Figures 2 and 3 represent the evolution of the velocity field at the free surface, that is, at the liquid-vapor interface during laser welding with a laser beam of power $P=2300$ $\mathrm{W}$ and scanning speeds $u_{s}=2.12$ and $4.23 \mathrm{~cm} / \mathrm{s}$ for $\theta=10^{\circ}$ and $170^{\circ}$. As explained above, the values of the absorptivities are taken to be $8 \%$ and $12 \%$ for $u_{s}=2.12$ and $4.23 \mathrm{~cm} / \mathrm{s}$, respectively. This implies that the absorbed power for the case of $u_{s}=4.23 \mathrm{~cm} / \mathrm{s}$, which is $276 \mathrm{~W}$, is higher than the absorbed power, $184 \mathrm{~W}$, for the case of $u_{s}=2.12 \mathrm{~W}$. For this reason, Figs. 2 and 3 show that the free surface velocities are higher for $u_{s}=4.23 \mathrm{~cm} / \mathrm{s}$ than those for $u_{s}=2.12 \mathrm{~cm} / \mathrm{s}$. These results illustrate that the melt velocity in the weld pool can be higher at higher scanning speed for a given laser

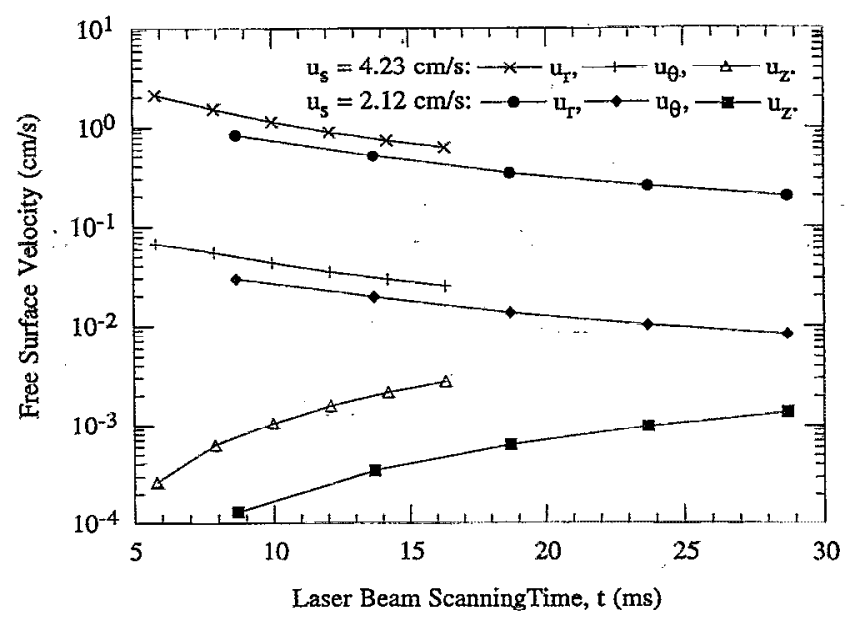

FIG. 3. Velocity components at $r=0.20041 \mathrm{~mm}$ and $\theta=170^{\circ}$ on the free surface during laser key-hole welding for incident laser power, $P=2300 \mathrm{~W}$ and laser beam radius, $r_{0}=0.3 \mathrm{~mm} . A=8 \%$ and $12 \%$ for $u_{s}=2.12$ and $4.23 \mathrm{~cm} / \mathrm{s}$, respectively. 


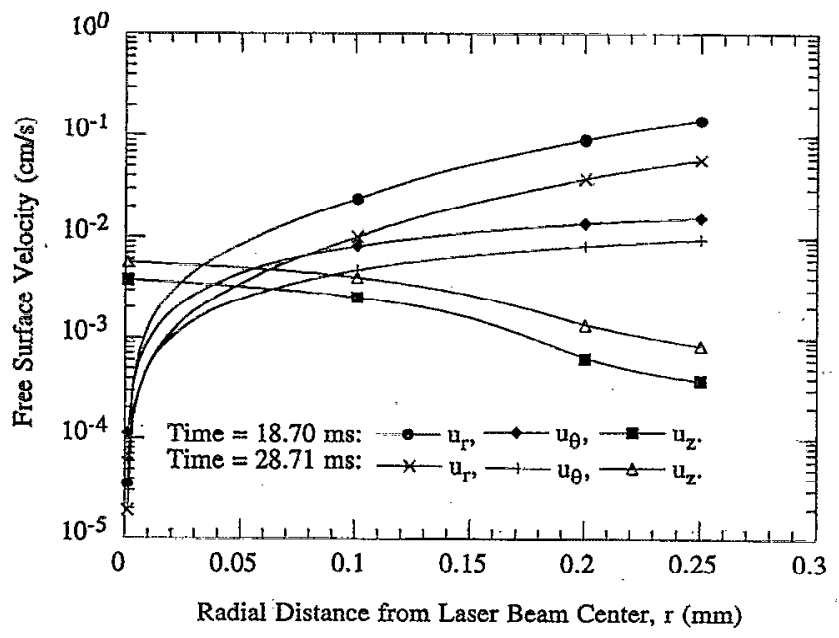

FIG. 4. Velocity components at $\theta=10^{\circ}$ on the free surface during laser key-hole welding for incident laser power, $P=2300 \mathrm{~W}$; laser beam radius, $r_{0}=0.3 \mathrm{~mm}$; laser beam scanning speed, $u_{s}=2.12 \mathrm{~cm} / \mathrm{s}$; and absorptivity, $A=8 \%$.

power if the laser-vapor interaction becomes significant. Also, Figs. 2 and 3 show that the radial and azimuthal velocities are dominant over the axial velocity at the beginning of the welding process and as the welding time increases, $u_{r}$ and $u_{\theta}$ decreases and $u_{z}$ increases. This effect can be understood by noting that the weld pool free surface is flat at the beginning of the welding process when the velocity field is mainly in the radial and azimuthal directions. However, as the welding time progresses, the free surface depresses, a key hole is formed and consequently, the axial velocity begins to increase.

Figures 4 and 5 represent the radial distributions of the free-surface velocity components for $\theta=10^{\circ}$ and $170^{\circ}$. These results also show that $u_{r}$ and $u_{\theta}$ decreases, and $u_{z}$ increases as the welding time increases. In laser-melted pools, the tem-

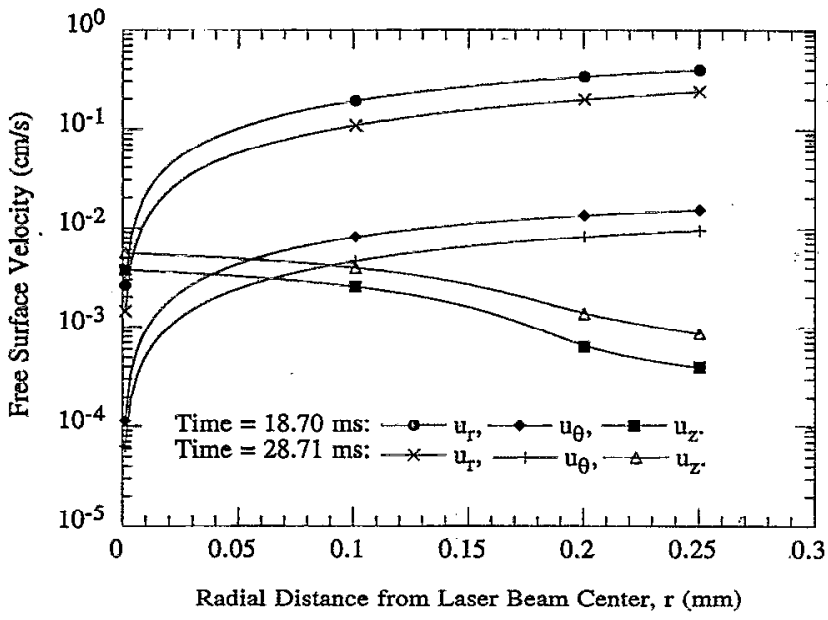

FIG. 5. Velocity components at $\theta=170^{\circ}$ on the free surface during laser key-hole welding for incident laser power, $P=2300 \mathrm{~W}$; laser beam radius, $r_{0}=0.3 \mathrm{~mm}$; laser beam scanning speed, $u_{s}=2.12 \mathrm{~cm} / \mathrm{s}$; and absorptivity, $A=8 \%$.

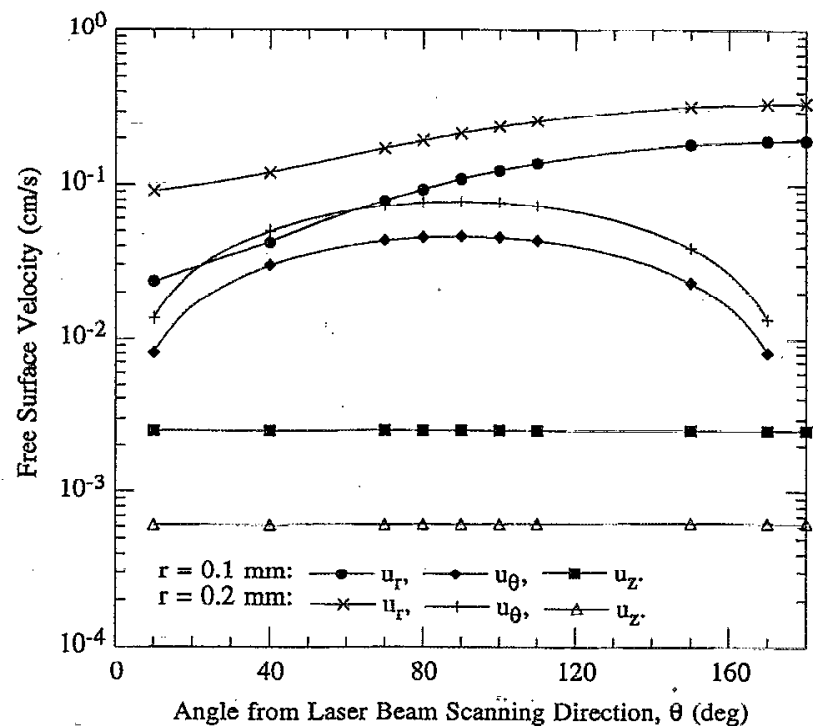

FIG. 6. Velocity components at the laser scanning time, $t=18.7 \mathrm{~ms}$ on the free surface for incident laser power, $P=2300 \mathrm{~W}$; laser beam radius, $r_{0}=0.3 \mathrm{~mm}$; laser beam scanning speed, $u_{s}=2.12 \mathrm{~cm} / \mathrm{s}$; and absorptivity, $A=8 \%$.

perature gradient is usually found to he higher in a certain region on the free surface between the center and solid-liquid interface of the pool than on the rest of the surface. This high-temperature gradient induces a high surface tension gradient which forces the melt to accelerate in this region. For this reason, $u_{r}$ and $u_{\theta}$ increases radially as shown in Figs. 4 and 5.

Figure 6 represents the azimuthal variations of the freesurface velocity components to indicate that the radial and azimuthal components are dominant over the axial component. The value of $u_{\theta}$ decreases near $\dot{\theta}=0^{\circ}$ and $180^{\circ}$ because there are stagnation points at the leading and trailing edges, which correspond to the points $\theta=0^{\circ}$ and $180^{\circ}$, respectively, at the solid-liquid interface, of the key hole. As in the case of Figs. 4 and 5 , this figure also shows that $u_{r}$ and $u_{\theta}$ increases as $r$ increases. The reason for $u_{r}$ increasing with the increase in $\theta$ is explained later in the context of Fig. 9.

The effect of laser power on the weld pool free-surface velocity is shown in Fig. 7 at two different azimuthal locations, that is, at $\theta=40^{\circ}$ and $150^{\circ}$. In this case, the absorptivity $A$ is taken to be the same (8\%) for all values of the incident laser power without accounting for the effect of laser-yapor interaction. Under this situation, $u_{r}$ and $u_{\theta}$ decrease as the laser power increases because higher laser power produces weld pools of larger size with reduced temperature gradient. As a result of this, the driving force for the melt flow decreases as laser power increases.

Figures 8-11 represent the temperature at the liquidvapor interface for various laser parameters as indicated in each of these figures. Figure 8 shows that the temperature is higher for higher scanning speed because the absorbed power is taken to be higher for the higher value of $u_{s}$ as explained for the results of Figs. 2 and 3 . Figure 9 represents the variation of temperature with the radius of the weld pool. The temperature is maximum at the center of the weld pool, 


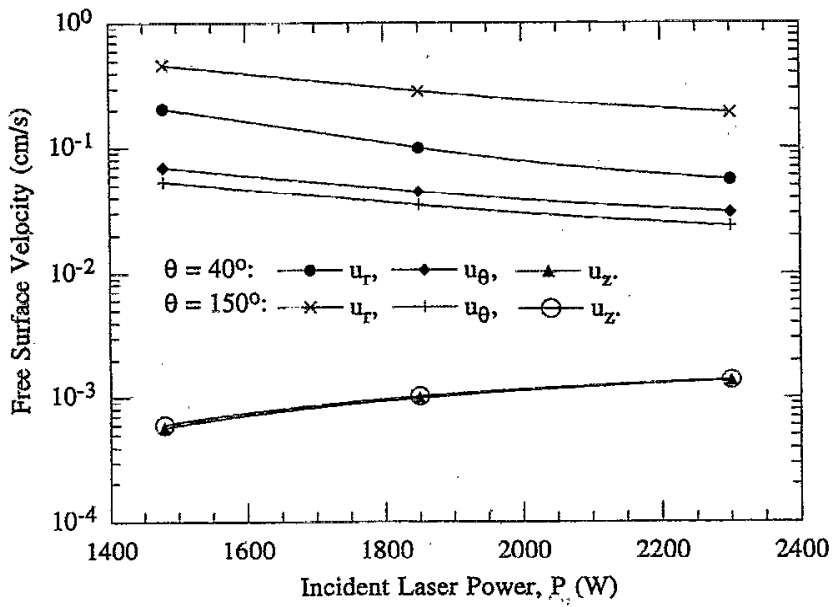

FIG. 7. Velocity components under quasisteady-state condition at $r=0.2$ $\mathrm{mm}$ on the free surface for laser beam radius, $r_{0}=0.3 \mathrm{~mm}$; laser beam scanning spced, $u_{s}=2.12 \mathrm{~cm} / \mathrm{s}$; and absorptivity, $A=8 \%$.

where $r=0$, and it decreases to the melting temperature at the outer edge of the weld pool, that is, at the solid-liquid interface. This figure shows that the magnitude of the temperature gradient is larger for $\theta=170^{\circ}$ than for $\theta=10^{\circ}$, which means that the surface tension gradient is higher in the trailing edge side than in the leading edge side of the key hole. For this reason, $u_{r}$ increases with the increase in $\theta$ as shown in Fig. 6.

Figure 10 shows that the temperature is higher in the leading edge side than in the trailing edge side of the key hole, because the leading and trailing edge sides are continuously heated and cooled respectively as the laser beam is scanned along the $\theta=0$ direction. The effect of laser power on the free-surface temperature is shown in Fig. 11. The results of this figure are obtained by taking the absorptivity $A$ to be the same $(8 \%)$ for all values of the incident laser power without accounting for the effect of laser-vapor interaction.

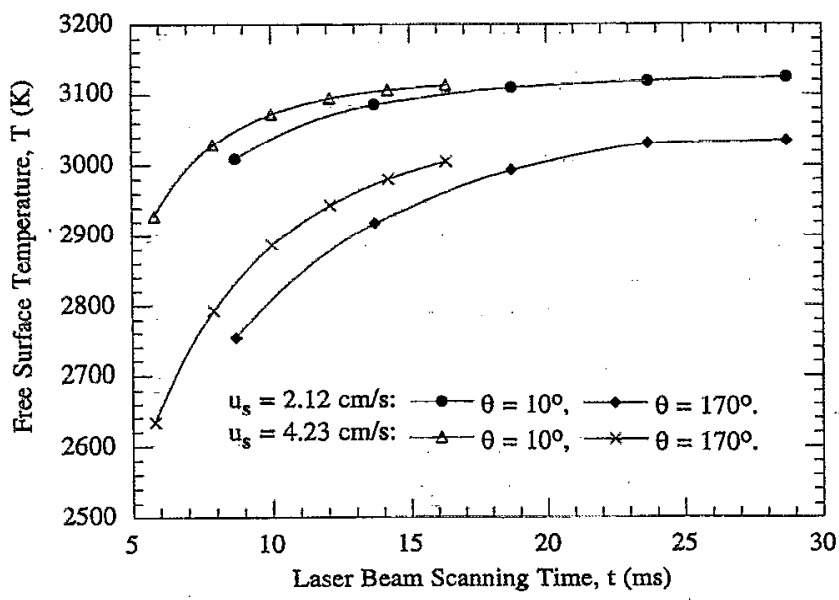

FIG. 8. Growth of liquid metal temperature at $r=0.2 \mathrm{~mm}$ on the free surface during key-hole welding for incident laser power, $P=2300 \mathrm{~W}$ and laser beam radius, $r_{0}=0.3 \mathrm{~mm} . A=8 \%$ and $12 \%$ for $u_{s}=2.12$ and 4.23 $\mathrm{cm} / \mathrm{s}$, respectively.

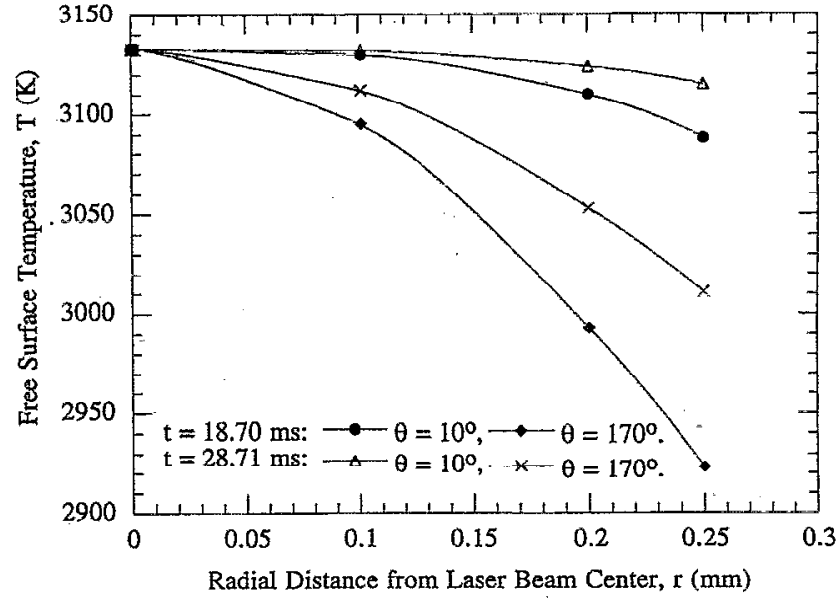

FIG. 9. Temperature of liquid metal at the free surface during key-hole welding for incident laser power, $P=2300 \mathrm{~W}$; laser beam radius, $r_{0}=0.3$ mm; laser beam scanning speed, $u_{s}=2.12 \mathrm{~cm} / \mathrm{s}$; and absorptivity, $A=8 \%$.

Figure 11 shows that the temperature increases as the absorbed power increases, and that the temperature in the leading edge side is higher than in the trailing cdge side of the key hole due to the reason explained above.

Figures 12-14 are concerned with the shape and size of the key hole. Figure 12 is obtained by plotting the solidliquid and liquid-vapor interfaces on the vertical plane that coincides with the laser beam scanning direction. This vertical plane is essentially the $\theta=0^{\circ}$ and $\theta=180^{\circ}$ plane, and the weld pool is symmetric about this plane. The center of the laser beam is located at the origin (0) of the horizontal axis in Fig. 12. The liquid-vapor and solid-liquid interfaces represent the depths of the key hole and melt pool, respectively. Figure 12 indicates that the depths increase as the welding time increases until the quasisteady state is reached, and that the depth of the melt pool increases more rapidly than the

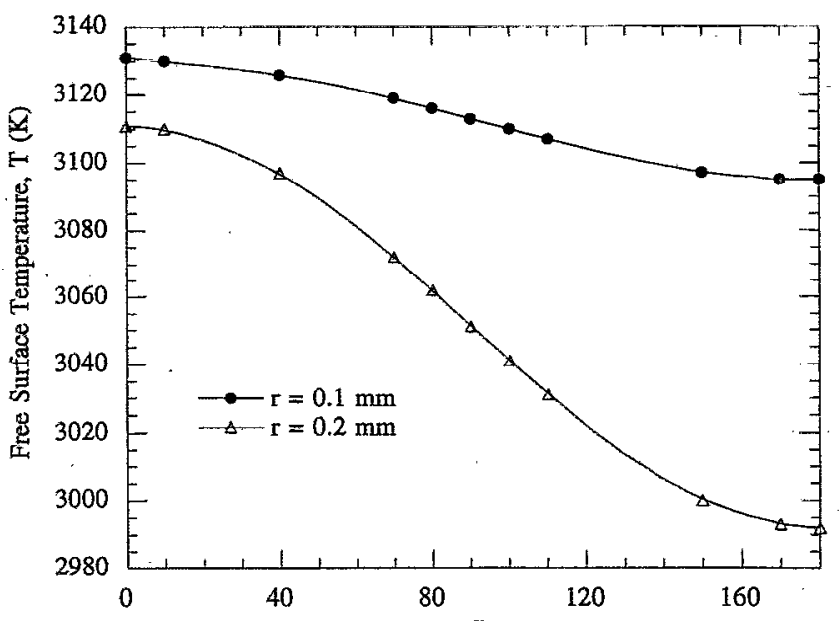

Angle from Laser Beam Scanning Direction, $\theta$ (deg)

FIG. 10. Temperature at $t=18.7 \mathrm{~ms}$ on the free surface during key-hole welding for incident laser power, $P=2300 \mathrm{~W}$; laser beam radius, $r_{0}=0.3$ mm; laser beam scanning speed, $u_{s}=2.12 \mathrm{~cm} / \mathrm{s}$; and absorptivity, $A=8 \%$. 


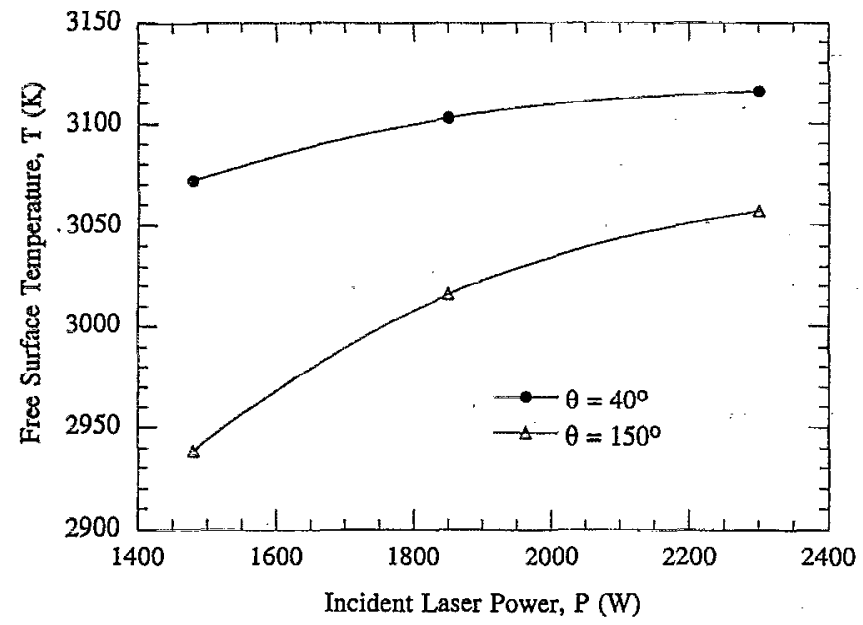

FIG. 11. Temperature of liquid metal under quasisteady-state condition at $r=0.2 \mathrm{~mm}$ on the free surface for laser beam radius, $r_{0}=0.3 \mathrm{~mm}$; laser beam scanning speed, $u_{s}=2.12 \mathrm{~cm} / \mathrm{s}$; and absorptivity, $A=8 \%$.

depth of the key hole as the welding time increases. Also, this figure shows that the leading solid-liquid interface, which is in front of the laser beam in the scanning direction, is closer to the center of the laser beam than the trailing solid-liquid interface which is behind the laser beam opposite to the scanning direction. The reason for this effect is that continuous heating occurs in front of the laser beam in the scanning direction, whereas cooling takes place behind the scanning beam.

Figure 13 represents the shape of the weld pool at the top surface of the workpiece. The intersection of the vertical and horizontal lines in the middle of this figure indicates the center of the laser beam which moves to the right along the horizontal line. The innermost curve in this figure is the liquid-vapor interface which represents the size of the mouth of the key hole at the substrate surface. The mouth of the key hole is found to be almost similar for the welding parameters used for plotting Fig. 13. However, the outer four curves,

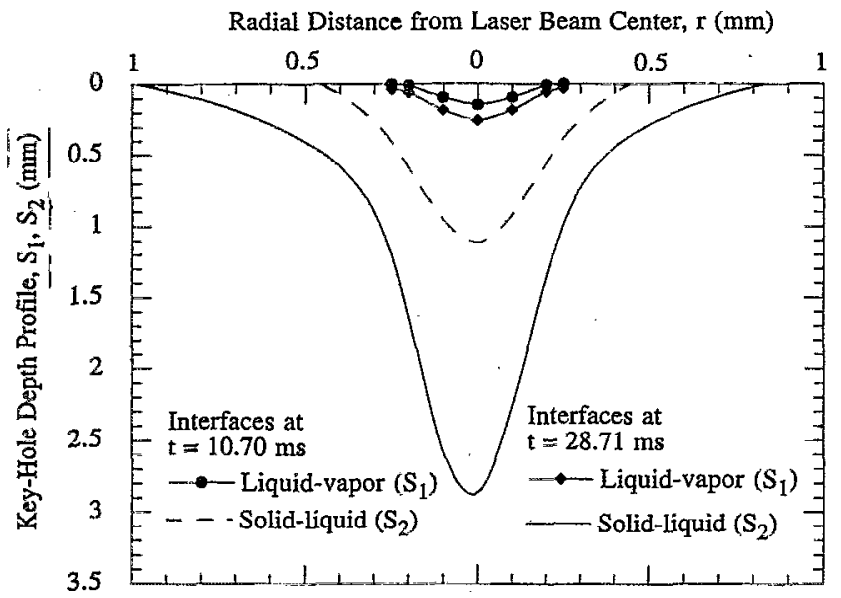

FIG. 12. Depth of the key holes formed during laser welding for incident laser power, $P=1850 \mathrm{~W}$; laser beam scanning speed, $u_{s}=2.12 \mathrm{~cm} / \mathrm{s}$; and absorptivity, $A=8 \%$.

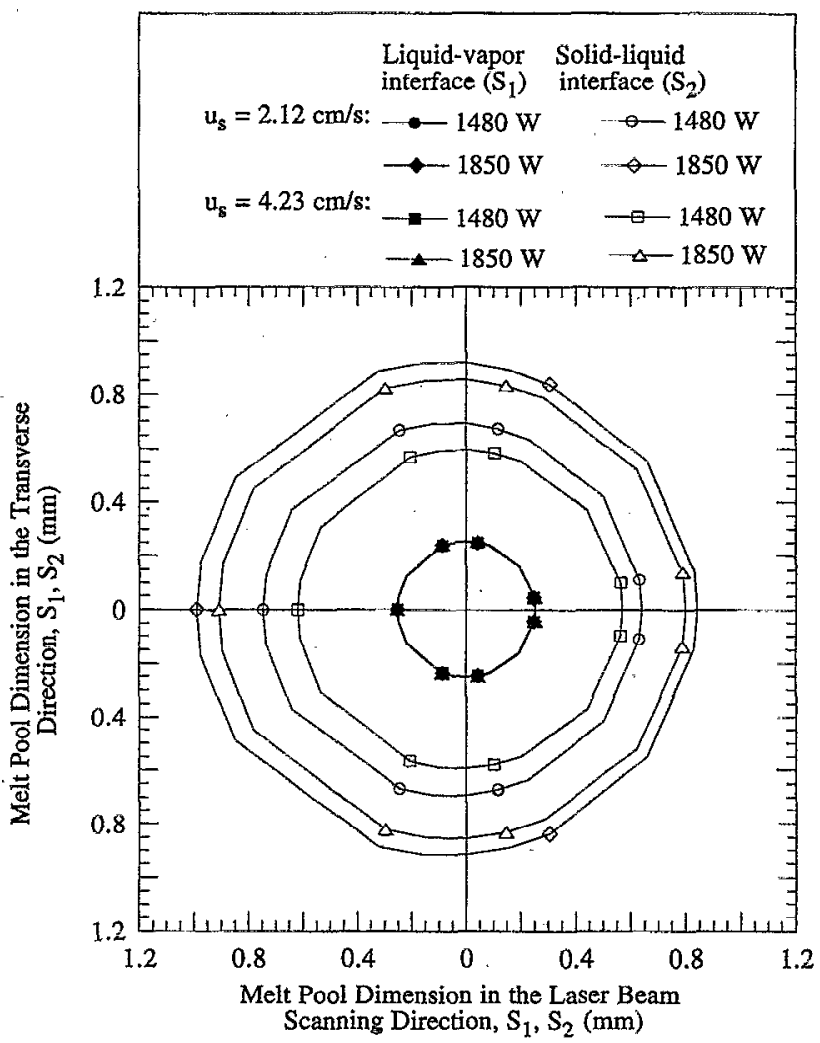

FIG. 13. Melt pool size and shape at the substrate surface under quasisteady-state condition. $A=8 \%$ for $P=1480$ and $1850 \mathrm{~W}$ when $u_{s}=2.12 \mathrm{~cm} / \mathrm{s} . A=17 \%$ and $15 \%$ for $P=1480$ and $1850 \mathrm{~W}$, respectively, when $u_{s}=4.23 \mathrm{~cm} / \mathrm{s}$.

which are the solid-liquid interfaces representing the sizes of the melt pool at the substrate surface, indicate that weld pools of different sizes can be obtained for different welding conditions. These four curves also show that the leading solid-liquid interface is closer to the center of the laser beam than the trailing solid-liquid interface.

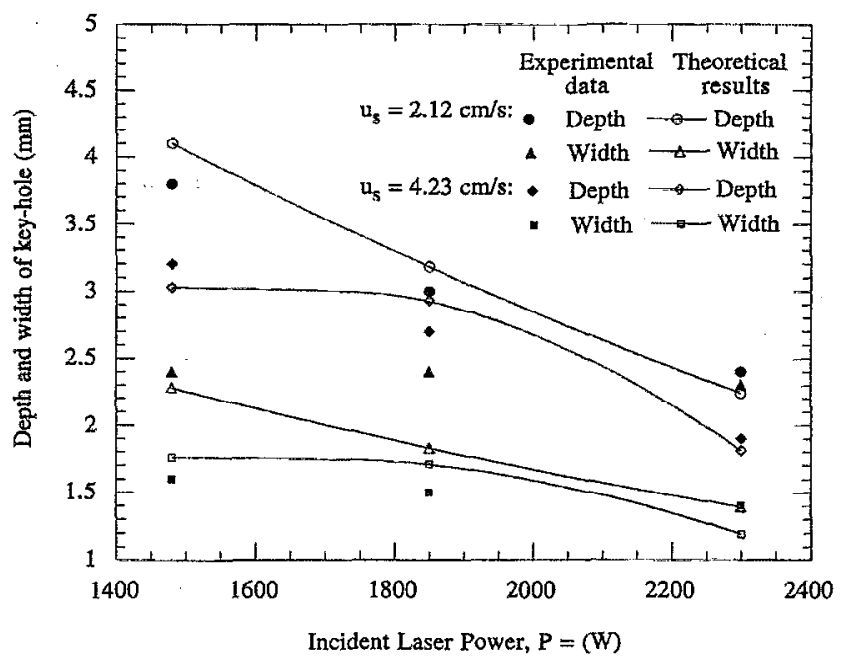

FIG. 14. Comparison of theoretical results with experimental data for the depth and width of key holes formed during laser welding, $A=8 \%$ for $P=1480,1850$, and $2300 \mathrm{~W}$ when $u_{s}=2.12 \mathrm{~cm} / \mathrm{s} . A=17 \%, 15 \%$, and $12 \%$ for $P=1480,1850$, and $2300 \mathrm{~W}$, respectively, when $u_{s}=4.23 \mathrm{~cm} / \mathrm{s}$. 
The maximum width and depth of the weld pool predicted by this model are compared with experimental data in Fig. 14. The maximum weld pool depth is obtained by determining the distance from the center of the laser beam at the substrate surface to the solid-liquid interface along the $z$ axis. The maximum weld pool width is obtained by determining the distance, which is measured along the transverse direction passing through the center of the laser beam at the substrate surface, between the solid-liquid interfaces. The predictions of this simple model are found to compare fairly well with the experimental data as shown in Fig. 14. To exactly predict the experimental data, more accurate thermophysical data have to be used, and a complex model involving the fluid dynamics, vaporization, condensation, and laservapor interactions has to be developed.

\section{CONCLUSION}

A mathematical model is developed for laser key-hole welding. This model can be used to determine the freesurface velocity and temperature distributions as well as the shape of the key hole. The results of this study lead to the following conclusions.

(1) The melt velocity in the weld pool can be higher at higher scanning speed for a given laser power if the laservapor interaction becomes significant.

(2) The radial and azimuthal velocities are dominant over the axial velocity at the beginning of the welding process and as the welding time increases, $u_{r}$ and $u_{\theta}$ decreases and $u_{z}$ increases.

(3) The magnitude of the temperature gradient is higher in the trailing edge side, which is behind the laser beam opposite to the scanning direction, than in the leading edge side which is in front of the laser beam in the scanning direction. Due to this, the surface tension gradient is higher in the trailing edge side than in the leading edge side of the key hole and consequently, $u_{r}$ is higher behind the laser beam than in front of the beam.

(4) The leading solid-liquid interface, which is in front of the laser beam in the scanning direction, is closer to the center of the laser beam than the trailing solid-liquid interface which is behind the laser beam opposite to the scanning direction.

(5) The depth of the weld pool (solid-liquid interface) increases more rapidly than the depth of the key hole (liquidvapor interface) as the welding time increases.

\section{ACKNOWLEDGMENT}

This work was made possible by a grant (N00014-89-J1473) from the Office of Naval Research. Dr. George Yader is the program manager.
${ }^{1}$ J. Mazumder, Opt. Eng. 30, 1208 (1991).

${ }^{2}$ A. L. Shaeffler, Br. Weld. J. 26, 601s (1947).

${ }^{3}$ H. E. Cline and T. R. Anthony, J. Appl. Phys. 48, 3895 (1977).

4J. G. Andrews and R. E. Craine, J. Fluid Mech. 84, 281 (1978).

${ }^{5}$ D. R. Atthey, J. Fluid Mech. 98, 787 (1980).

${ }^{6}$ S. Kou, S. C. Hsu, and R. Mehrahian, Metall. Trans. 12B, 33 (1981).

${ }^{7}$ G. M. Oreper, T. W. Eager, and J. Szekely, Welding J. 63, 307s (1983).

${ }^{8}$ G. M. Oreper and J. Sxekely, J. Fluid Mech. 147, 53 (1984).

${ }^{9}$ C. Chan, J. Mazumder, and M. M. Chen, Mctall. Trans. 15A, 2175 (1984).

${ }^{10} \mathrm{C}$. Chan, J. Mazumder, and M. M. Chen, Mater. Sci. Tech. 3, 306 (1987).

${ }^{11}$ C. Chan, J. Mazumder, and M. M. Chen, J. Appl. Phys. 64, 6166 (1988).

${ }^{12}$ S. Kou and Y. H. Wang, Welding J. 65, 63s (1986).

${ }^{1.3}$ S. Kou and D. K. Sun, Metall. Trans. 16A, 203 (1985).

${ }^{14} \mathrm{~S}$. Kou and Y. H. Wang, Metall. Trans. 17A, 2265 (1986).

${ }^{15}$ B. Basu and J. Srinivasan, Int. J. Heat Mass Transter 31, 2331 (1988).

${ }^{16}$ B. Basu and A. W. Date, Int. J. Heat Mass Transfer 33, 1149 (1990).

${ }^{17}$ B. Basu and A. W. Date, Int. J. Heat Mass Transter 33, 1165 (1990).

${ }^{18}$ T. R. Anthony and H. E. Cline, J. Appl. Phys. 48, 3888 (1977).

${ }^{19}$ T. Zacharia, A. H. Eraslan, and D. K. Aidun, Weld. J. 67, 18s (1988).

${ }^{20}$ T. Zacharia, A. H. Eraslan, and D. K. Aidun, Weld. J. 67, 53s (1988).

${ }^{21}$ M. C. Tsai and S. Kou, Weld. J. 69, 241s (1990).

${ }^{22}$ A. Paul and T. Debroy, Metall. Trans. 19B, 851 (1988).

${ }^{23}$ M. C. Tsai and S. Kou, Int. J. Numer. Meth. Fluids 9. 1503 (1989).

${ }^{24}$ M. C. Tsai and S. Kou, Numer. Heat Trans., Part A: Applications 17, 73 (1990).

${ }^{25}$ E. W. Kreutz and N. Pirch, in Industrial and Scientific Uses of High Power Lasers, Proc. Soc. Photo-Opt. Instrumentation Eng. Vol. 1502, edited by J. P. Billon and E. Fabre (SPIE-The Int. Soc, for Optical Engineering, Washington, 1991), p. 160.

${ }^{26} \mathrm{R}$. L. Zehr, Ph. D. thesis, University of Illinois at Urbana-Champaign, 1991.

${ }^{27}$ M. E. Thompson and J. Szekely, Int. J. Heat Mass Transfer 32, 1007 (1989).

${ }^{28}$ R. T. C. Choo, J. Szekely, and R. C. Westhoff, Weld. J. 69, 346s (1990).

${ }^{29}$ J. Dowden, N. Postacioglu, M. Davis, and P. Kapadia, J. Phys. D 20, 36 (1987).

${ }^{30}$ N. Postacioglu, P. Kapadia, M. Davis, and J. Dowden, J. Phys. D 20, 340 (1987).

${ }^{31}$ W. M. Steen, J. Dowden, M. Davis, and P. Kapadia, J. Phys. D 21, 1255 (1988).

${ }^{32}$ R. Akhter, M. Davis, J. Dowden, P. Kapadia, M. Ley, and W. M. Steen, J. Phys, D 21, 23 (1989).

${ }^{33}$ J. Dowden, P. Kapadia, and N. Postacioglu, J. Phys. D 22, 741 (1989).

${ }^{34}$ J. Dowden, W. S. Chang, P. Kapadia, and C. Strange, J. Phys. D 24, 519 (1991).

${ }^{35}$ M. Beck, P. Berger, and H. Hügel, in Laser Treatment of Materials, Proc. European Conference on Laser Treatment of Materials, 1992 (ECLAT'92), edited by B. L. Mordike (DGM Intormationsgesellachaft mbH, Adenauerallee 21, D-6370 Oberursel 1, 1992), p. 693.

${ }^{36}$ E. A. Metzbower, Metall. Trans. 24B, 875 (1993).

${ }^{37}$ S. G. Lambrakos, E. A. Metzbower, J. H. Dunn, and P. G. Moore, in International Trends in Welding Science and Technology, edited by $\mathrm{S}$. A. David and J. M. Vitek (ASM International, Materials Park. Ohio, 1993), p. 51.

${ }^{38}$ C. Tix and G. Simon, J. Phys, D 25, 2066 (1993).

${ }^{39}$ J. Kroos, U. Gratzke, and G. Simon, J. Phys. D 26, 474 (1993).

${ }^{40}$ J. Kroos, U. Gratzke, M. Vicanek, and G. Simon, J. Phys. D 26, 481 (1993).

${ }^{11}$ G. K. Batchelor, An Introduction to Fluid Mechanics (Cambridge University Press, New York, 1980), pp. 147-173.

${ }^{42}$ F. M. White, Viscous Fluid Flow (McGraw-Hill, New York, 1974), pp. $171-181$. 